\title{
Radiofrequency upper thoracic sympathectomy in the treatment of critical upper limb ischemia - a case series
}

\author{
Tomas Gabrhelika, Daniel Stehlik ${ }^{\mathrm{b}}$, Milan Adamus ${ }^{\mathrm{a}}$, Bohumil Zalesak ${ }^{\mathrm{b}}$, Pavel Michalek ${ }^{\mathrm{c}}$
}

\begin{abstract}
Background. Patients with significant medical and social problems resulting from impaired perfusion of the upper limbs caused by micro- or macro-angiopathy are now frequent in clinical practice. Vasospastic disease of the upper limbs of combined origin is a difficult condition to treat by conservative methods and therapeutic strategies are usually multidisciplinary. In addition to standard pharmacotherapy, treatment may involve regional anaesthesia, thoracoscopic or radiofrequency sympathectomy and surgical treatment of defects, including plastic surgery.

Methods. This paper describes our successful work in the treatment of upper limb critical ischemia using radiofrequency upper thoracic sympathectomy.

Results. In three case reports we present the results of radiofrequency thermolysis applied to treat patients with chronic defects of the hand and fingers. These patients were diagnosed with upper limb critical ischemia of combined origin, standard conservative treatment methods failed and surgical intervention was originally not indicated, however, radiofrequency thermolysis proved to be beneficial.
\end{abstract}

Conclusions. Radiofrequency thoracic sympathectomy could improve peripheral perfusion of the upper limbs and thereby contribute to healing of chronic defects, reduction of pain and improvement in the quality of life of the patients.

Key words: radiofrequency upper thoracic sympathectomy, upper limb critical ischemia, chronic hand defects, multidisciplinary treatment strategy

Received: July 2, 2011; Accepted with revision: October 19, 2011; Available online: November 1, 2011

http://dx.doi.org/10.5507/bp.2011.055

${ }^{a}$ Department of Anaesthesiology and Intensive Care Medicine, University Hospital Olomouc and Faculty of Medicine and Dentistry, Palacky University Olomouc, Czech Republic

${ }^{b}$ Department of Plastic and Aesthetic Surgery, University Hospital Olomouc and Faculty of Medicine and Dentistry, Palacky University Olomouc

'Department of Anaesthesia, Resuscitation and Intensive care medicine, $1^{\text {st }}$ Medical Faculty Charles University and General University Hospital in Prague

Corresponding author: Tomas Gabrhelik, e-mail: tomas.gabrhelik@fnol.cz

\section{INTRODUCTION}

\section{Critical upper limb ischemia}

The causes of critical upper limb ischemia are very variable. Among the most frequent causes of peripheral arterial occlusions are atherosclerosis or complications of type 1 and type 2 diabetes mellitus (microangiopathy, macroangiopathy and neuropathy). Specific causes of upper limb arterial occlusions include peripheral embolisation of central (heart, aortic arch) or peripheral origin (posttraumatic false aneurysms, dissections) which may induce or potentiate the vasospastic response.

Vasospastic events as a part of other diseases are called secondary Raynaud's phenomenon (previously called syndrome). Other causes include collagen disorders, various haematological diseases, recurrent thromboflebitis, thoracic outlet syndrome or vibration trauma. Patients complain of permanent pain in the fingers, which deteriorate in cold environments. However, the convulsive character of pain is usually missing. The impairment of fingers is asymmetrical. This may progress up to ulcerative gangrene lesions on the tips of fingers, severe pain at rest and restriction of motion in interphalangeal joints.
If the peripheral vasospasm occurs from unknown causes, we call it a primary Raynaud's phenomenon (previously called disease). Raynaud's phenomenon was first described by Maurice Raynaud in 1862. It is characterized by paroxysmal blanching of the skin on the fingers, mainly of the upper limbs, triggered by cold or stress. Raynaud's phenomenon is the most frequent cause of functional disorders of upper limb perfusion. This condition affects mostly women with a prevalence of $3-5 \%$ and it has a progressive character ${ }^{1}$. In comparison with the secondary form, there are usually no trophic changes.

Extravascular Raynaud's phenomenon is a group of diseases caused by spasm of the peripheral arteries without organic impairment, during which however we know the agent or underlying disease, which causes arterial spasm $^{2}$. This group includes Raynaud's phenomenon induced by medication, concomitant neurological diseases, intoxication, paraneoplastic Raynaud's phenomenon or iatrogenic arterial spasms during angiography.

Conservative therapy of upper limb vasospastic diseases includes medication that suppresses vasoconstriction (ACE inhibitors, serotonin reuptake inhibitors), vasodilatation substances (prostanoids), antiaggregation 
therapy (ticlopidin, ibustrin, acetylsalicylic acid) or medication affecting rheological parameters in microcirculation. Thorough observation of preventive measures such as avoidance of smoking and cold ${ }^{3}$ is sufficient in mild forms. Secondary forms require treatment of the underlying disease. If the symptoms of the upper limb perfusion disorders progress and impair the quality of life of the patient, there is invasive therapy indicated in case of conservative therapy failure. Standard method of choice is thoracoscopic upper thoracic sympathectomy. In case the patient did not agree with the surgical procedure or anaesthesia was contraindicated, percutaneous chemical sympathectomy was previously performed. It has recently been replaced by safer radiofrequency upper thoracic sympathectomy (hereinafter referred to as RF-TSE).

\section{Radiofrequency therapy}

Radiofrequency (hereinafter called RF) therapy is a minimally invasive method utilising the effect of alternating electric fields of high frequency on the nerve tissue. Electric current flows to the target structure via percutaneously introduced isolated needle with an active tip, which has the function of an electrode (anode). When the tissue is exposed to the effect of alternating radiofrequency current, there is heat produced, since the surrounding tissue acts as a resistor to the passage of the current. This results in heat destruction of the nerve fibres (RF thermoablation). Temperature detected from the active tip of the electrode is equal to the temperature at the site of the lesion. The neurodestructive effect of temperature begins at $60{ }^{\circ} \mathrm{C}$, when proteins undergo coagulation; reversible are considered the effects of temperatures below $45^{\circ} \mathrm{C}$. The temperature gradient decreases from the centre to periphery. For this reason more distal structures are exposed only to lower temperatures.

However, production of heat is not the only factor responsible for the analgesic effect of the procedure. RF field has a biological effect on nerve tissue, which is not dependent on temperature. The effect of the electric field results in temporary electrophysiological changes in pain conduction and thereby results in modulation of excitation synaptic transmission ${ }^{4}$. The method utilising nondestructive neuromodulation effect of RF field on nerve tissue is called pulsed RF (ref. ${ }^{5}$ ).

The most frequent indications for RF therapy include vertebrogenic pain (facet, discogenic and radicular pain), sympathetically maintained pain, limb perfusion disorders and neuropathic pain. RF-TSE at the level of the second and third thoracic vertebra (hereinafter T2 and T3) is used for the treatment of perfusion disorders, Raynaud's phenomenon and upper limb hyperhidrosis. Contraindications include disorders of blood clotting, local infections and implanted pacemakers. The basic equipment is a microprocessor controlled generator of RF current, part of which is a neurostimulator of motor and sensitive fibres. Selective neurostimulation enables perfect control of active needle tip placement with regard to the target structure. An isolated needle is introduced under local anaesthesia to the target structure under fluo- roscopic control using a $\mathrm{C}$-arm with the direction of the needle parallel to the $\mathrm{X}$ rays ("Tunnel Vision Technique“).

\section{MATERIAL AND METHODS}

Informed consent in all cases was obtained. The procedures were performed on an outpatient basis in the operation theatre under fluoroscopic control. The patient was placed in a prone position with elevated arms and head in neutral position. There was intravenous analgosedation used for the procedures (sufentanil 5-10 $\mu \mathrm{g}$ ). We localised the T2 and T3 vertebrae in the postero-anterior view using fluoroscopy. After marking the site of the puncture at the lower part of the vertebral body we performed local anaesthesia using $1 \%$ trimecaine. Simultaneously with the axis of the C-arm according to the rules of the "Tunnel Vision Technique" we introduced a $20-\mathrm{G}$ radiofrequency isolated needle (TycoHealthcare, USA) with $5 \mathrm{~mm}$ active tip in tangential view $25-30^{\circ}$ (ref. $^{6}$ ). The depth of needle introduction was controlled in lateral view and the final position of the tip was in the middle of the lateral aspect of the vertebral body. In the postero-anterior view the tip of the needle was located slightly medially from the edge of the vertebral body. After negative aspiration non-ionized contrast substance was administered spreading cranially and caudally along the edge of the vertebra (Fig. 1). We used neurostimulation test to verify the final position of the active tip of the needle electrode. Initially we performed neurostimulation of sensitive fibres at a frequency of 50 $\mathrm{Hz}$, later also motor fibres at a frequency of $2 \mathrm{~Hz}$. If there was paraesthesia induced on the medial aspect of the arm (intercostobrachial nerves) or in the area of the innervation zone of the second and third intercostals nerve, the direction of the needle tip was targeted ventrally ${ }^{7}$. After

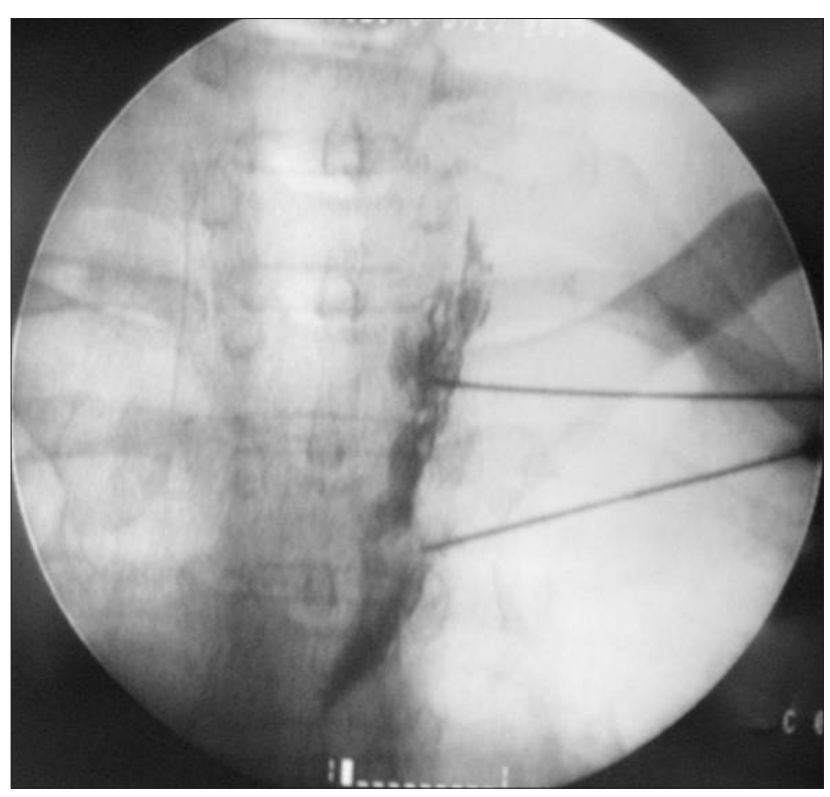

Fig. 1. RF-TSE at the level of T2 and T3 - X-ray image in the antero-posterior view after administration of contrast substance. 
a positive result of neurostimulation was administered 1 $\mathrm{ml}$ of $1 \%$ trimecaine for anaesthesia of the sympathetic nerves. We performed 2 cycles of RF thermolesion with a duration of $60 \mathrm{~s}$ and temperature of $80{ }^{\circ} \mathrm{C}$ at the level of T2 and T3 (ref. ${ }^{8}$ ). We used the RF generator Radionics RFG-3C Plus (Radionics Inc., USA) for the procedure. After the procedure vital functions were monitored in the recovery unit and before discharge was assessed pain, condition of the puncture site and general neurological functions. The patient received contact telephone number to report possible complications or adverse effects.

\section{RESULTS}

\section{Case report 1}

A 34-year old woman suffered from multi-organ impairment caused by type 1 diabetes mellitus. She also had a history of dyslipidemia, Hashimoto thyroiditis, steatosis of the liver, a condition after acute pancreatitis. Polyneuropathy and chronic renal insufficiency developed also as a consequence of the underlying disease. The patient underwent regular haemodialysis using an AV shunt in the left antecubital fossa. She was withdrawn from the transplantation program for low compliance as a consequence of incidental brain atrophy. In 2010 diabetic micro and macroangiopathy on the left upper limb was diagnosed. She developed recurrent thrombophlebitis. Since
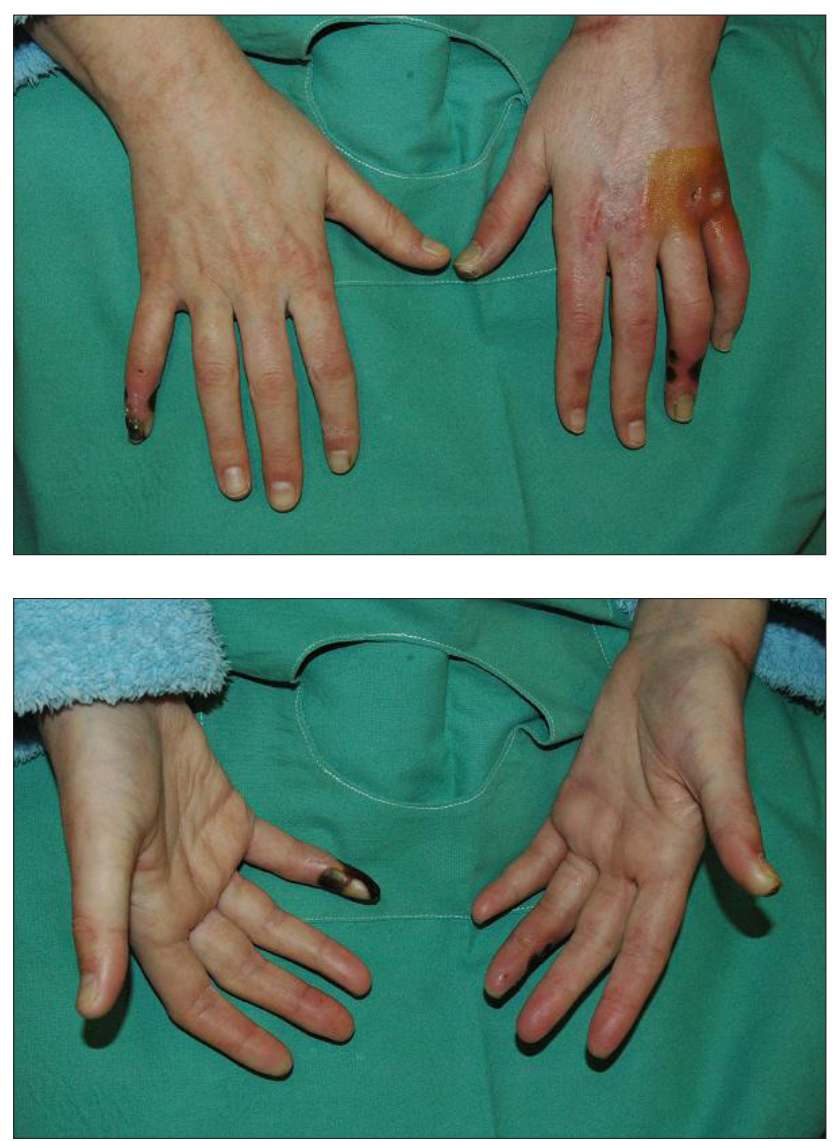

Fig. 2. Case 1 - ischemic necroses on the fingers of both hands.
August 2010 she developed small ischemic necroses on the fingers of both hands and in the area of the metacarpo-phalangeal joint on the sole of the right foot. Necroses progressed to chronic full thickness skin defects despite intensive local therapy, good compensation of diabetes and administration of vasodilatation therapy (Fig. 2).

The treatment of the patient was managed by a multidisciplinary team (diabetology specialist, vascular surgeon, plastic surgeon, clinical psychologist), but the effect of conservative therapy was minimal. As the macrooangiopathy was diagnosed with MRI, vascular surgery was considered. Perfusion of the left upper limb however deteriorated due to an A-V shunt. It improved after performance of percutaneous transluminal angioplasty but ischemic lesions on the right hand subsequently developed. No additional vascular intervention was performed and conservative therapy for 4 weeks was not effective. Due to the general condition of the patient (co-morbidities) was indicated RF - TSE after a consultation. Immediately after performance of RF thermolysis of sympathetic nerves at the level of T2 - T3 on the right side, the patient reported sensation of warm hands. The defects of both hands gradually healed one month after the procedure with continuous local therapy using a combination of colloid dressing and active Ag. Complete healing of the ischemic lesions of the hand was achieved in 7 weeks. The condition was prolonged by repeated decompensations of diabetes with low patient compliance. In spite of this the effect of therapy lasted as long as 8 months after RF sympathectomy.

\section{Case report 2}

A 58-year old male treated with secondary Raynaud's phenomenon as an occupational disease ("hammer syndrome"). The patient worked for 35 years as a smith. He had been treated with insulin for type 2 diabetes mellitus that was complicated with macroangiopathy diagnosed by digital subtraction angiography. The impairment of arteries in the upper limbs was greater on the right side; the occlusion of radial and ulnar arteries was compensated by abundant collateral circulation. Vascular intervention or radiologically assisted angioplasty was not indicated by the specialist. The local condition significantly deteriorated after the development of $3^{\text {rd }}$ degree burn during work with a hot iron. Non-healing defects developed in the area of the $1^{\text {st }}-3^{\text {rd }}$ finger of the right hand (Fig. 3a). After 6 months from the injury and despite local and systemic vasodilatation therapy with good compensation of diabetes there was a deterioration of ischemia of the $2^{\text {nd }}$ finger. Due to the inability of surgical or radiological intervention was performed exarticulation in MP joint after a rapid development of gangrene of the distal and middle phalanx of the $2^{\text {nd }}$ finger. Stump of the $2^{\text {nd }}$ finger has not healed and also there was a risk of gangrene in the area of the defects of the $1^{\text {st }}$ and $3^{\text {rd }}$ finger of the right hand. Diagnostic block of ganglion stellatum on the right side was indicated. After a positive result of the block RFTSE was performed on the right side $\left(80{ }^{\circ} \mathrm{C}, 60 \mathrm{~s}\right.$, levels $\mathrm{T} 2$ and T3). The procedure was accomplished without 


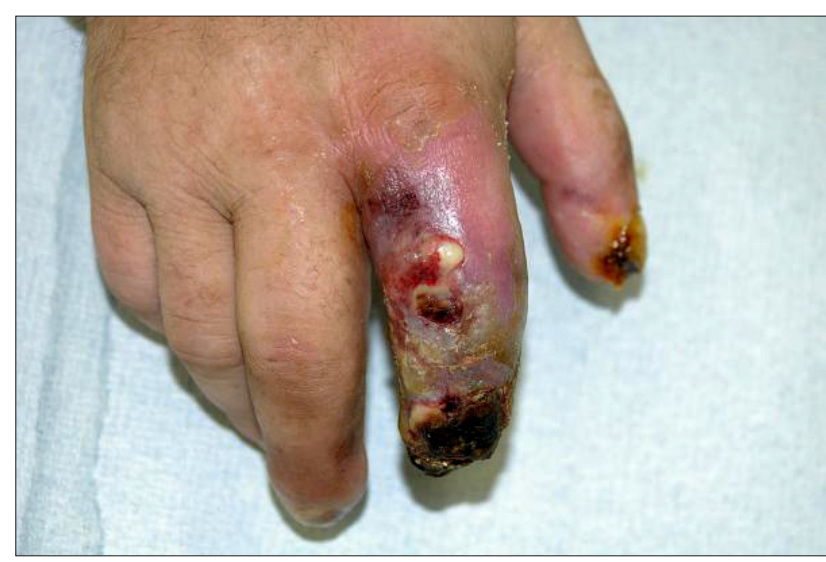

Fig. 3a. Case 2 - non-healing s of the right hand.

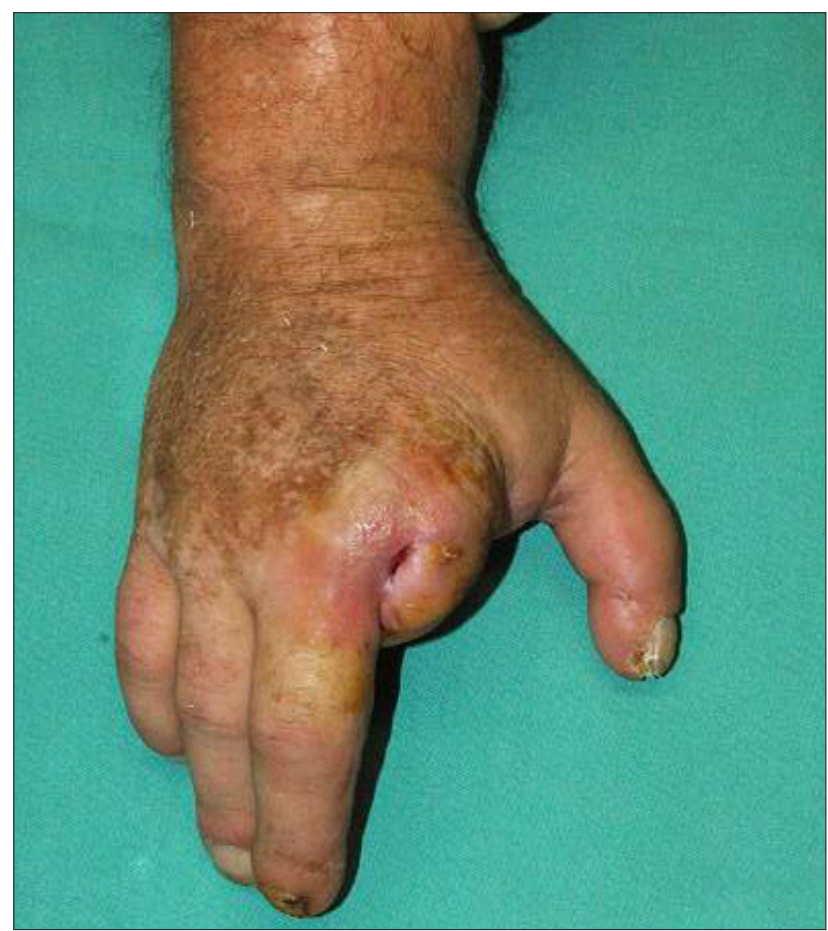

Fig. 3b. Case 2 - healed defect after the amputation.

any complications, the patient reported 2 days of pain at the puncture site. The stump on the $2^{\text {nd }}$ finger after the amputation healed three weeks after the procedure (Fig. 3b). Complete closure of ischemic lesions of the $1^{\text {st }}$ and $3^{\text {rd }}$ finger of the right hand was observed in 2 months after RF-TSE. Active Ag products and hyaluronic acid were used for local therapy in combination with barrier polyurethane dressing. Healed condition of the ischemic lesions lasts also 12 months after RF therapy.

\section{Case report 3}

A 43-year old male, followed up for approx. 5 years for Raynaud's syndrome. The patient sustained contusion of the left thumb at work (non dominant hand) in the area of the distal phalanx of minor extent (Fig. 4a). In spite of intensive vasodilatation therapy rapid progress of

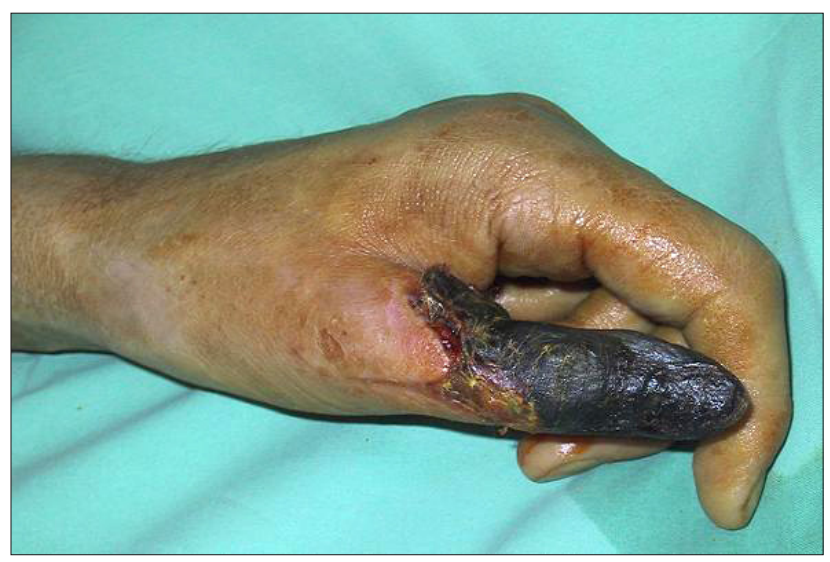

Fig. 4a. Case 3 - ischemic necrosis of all soft tissue structures of the thumb.

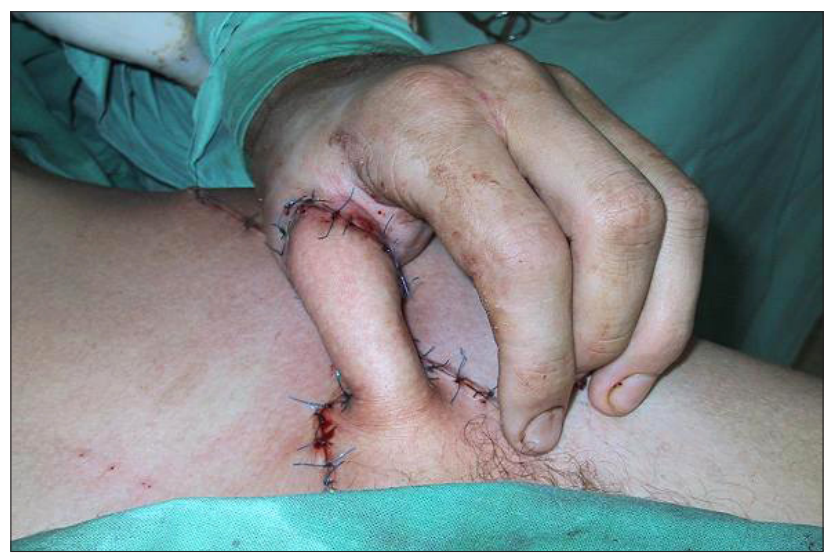

Fig. 4b. Case 3 - coverage of the defect with a pedicled groin flap after necrectomy.

ischemic necrosis of all soft tissue structures of the thumb was observed. Ultrasound examination had shown normal blood perfusion on the radial artery and ulnar artery on the left side. Due to rapid progress of post-traumatic ischemia during the underlying disease was indicated radiofrequency upper thoracic sympathectomy. After a positive diagnostic block was performed RF-TSE at the level T2 and T3 on the left. The first day after the procedure was observed significant improvement of the perfusion of the left hand and subjective reduction of pain. Within 7 days after RF-TSE there was demarcation of the necrosis observed; necrectomy was performed and subsequently a plastic surgeon performed coverage of the defect with a pedicled groin flap (Fig. 4b). Subsequent healing was uncomplicated. The result could not be documented by photography as the patient moved abroad. According to a telephone contact is the patient's problem healed for 2 years now, vasospastic complaints persist only during winter period of the year. 


\section{DISCUSSION}

The causes of upper limb vasospastic diseases and mainly primary Raynaud's phenomenon have not been clearly explained yet. In general, genetic factors, hormonal factors (mainly women are affected), mental stress and smoking contribute to the development of the disease. Mechanisms and causes of Raynaud's phenomenon may be divided to vascular, neurogenic and intravascular? Vascular causes included changes in the structure of the vascular wall as well as the function of endothelium accompanied by a local deficit of prostacycline and nitrogen oxide ${ }^{10}$ or increased level of angiotensin II (ref. $\left.{ }^{11}\right)$. Neurogenic causes include stress, increased activity of sympathetic nerves, increased number and activation of silent $\alpha 2$ receptors ${ }^{12}$, depletion of neurokinin A, substance $\mathrm{P}$ and CGRP (calcitonin gene-related peptide) $\left(\right.$ ref. ${ }^{13}$ ). Intravascular disorders include activation of platelets with increased level of thromboxan, disorder of fibrinolysis, activation of leukocytes, reduced deformability of erythrocytes and increased viscosity.

These facts are important in the conservative management of vasospastic disease of the upper limbs. This includes medication that suppresses vasoconstriction (ACE inhibitors, serotonin reuptake inhibitors), vasodilatation substances (prostanoids) or substances affecting rheological parameters within the microcirculation. Thorough observation of preventive measures such as avoidance of smoking and $\operatorname{cold}^{3}$ is sufficient in mild forms. In case of secondary forms, it is necessary to treat the underlying disease. Conservative therapy of vasospastic conditions includes medication suppressing vasoconstriction, vasodilatation substances or medication affecting the rheological parameters within the microcirculation. The efficiency of nifedipin on reduction of intensity and frequency of vasospastic attacks is demonstrated in a meta-analysis ${ }^{1}$. Similar results are demonstrated also in case of felodipin and amlodipin therapy. Metaanalysis has confirmed efficiency also for infusion therapy with iloprost in the treatment of secondary Raynaud's phenomenon based on scleroder$\mathrm{mia}^{14}$. Individual randomized controlled studies report effect of therapy with losartan, fluoxetine or sildenafil, but also pentoxyphylline, xantinolnicotinate, thymoxamine, dihydroergotoxine, heparin, prazosine, guanethidine or gingkoflavonoids ${ }^{15}$.

The results of conservative therapy of vasospastic conditions are not always convincing, medication only reduces convulsive tendency and attenuates their course. Upper thoracic sympathectomy is a therapeutic method of choice in patients with functional disorders of upper limb perfusion, if the attacks significantly affect quality of life or conservative therapy fails. Preferred procedure in this indication is thoracoscopic upper thoracic sympathectomy ${ }^{16}$. The advantage of surgical procedure is direct visualisation of the sympathetic chain and thereby also high success of the method. On the other hand, the operation is associated with the risks of general anaesthesia, selective intubation with unilateral lung ventilation and collapse of the lung with capnothorax. Matsumoto reports in his study from 2002 an immediate success in almost 93\%. Although most patients with disorders of perfusion in the upper limbs experienced recurrence of complaints, after more than 5 years there was reduction of frequency and severity of attacks reported in $89.3 \%$ of patients ${ }^{17}$. Thune reports short term success of thoracoscopic sympathectomy of $83 \%$ in a group of 34 patients with Raynaud's phenomenon ${ }^{18}$. Long term effect however was reported only in one third of the patients. There are limitations of this method - occurrence of pleural adhesions, severe cardiovascular disorder or respiratory insufficiency. In the postoperative period there is a risk of developing pneumothorax, hemothorax, atelectasis, Horner's syndrome, intercostal neuralgia or secondary erythromegalia. Due to frequent incidence of adverse events is thoracoscopic sympathectomy used only in severe disorders of upper limb perfusion.

Percutaneous chemical neurolysis of sympathetic nerves was first performed in the 30's of the last century ${ }^{19}$. The administration of a total volume of $6 \mathrm{ml}$ of $6 \%$ phenol in two levels there is however a high risk of damage of the surrounding structures by the neurolytic agent ${ }^{20}$. This method was abandoned after the introduction of RF thermolysis.

Destruction of sympathetic nerves caused by heat occurs in case of the RF thermoablation. Interruption of these nerves similarly as in case of thoracoscopic sympathectomy results in better perfusion of the upper limbs. Sympathetic fibres from the upper cervical and upper thoracic ganglia contribute to the sympathetic innervation of the upper limbs; the connecting junction is the ganglion at the level of the second thoracic vertebra ${ }^{21}$. Sympathetic bundle in the upper thoracic levels is located on the lateral side of the vertebral bodies, which results in difficult procedure due to close relation to pleura, vessels and spinal nerves ${ }^{22}$. Combination of several safety features minimises the damage to the surrounding tissues caused by RF thermolesion. This includes localisation of the tip of the needle and control of distribution of the contrast substance using imaging methods (fluoroscopy with mobile C-arm, CT), measurement of surrounding tissue impedance, neurostimulation tests and possibility to set the temperature and time of the lesion. Size of the lesion around $5 \mathrm{~mm}$ active tip of the needle is well known (diameter 3-5 mm). Complications are determined by the proximity of parietal pleura, which is almost adhering to the lateral side of the vertebral bodies at the site, where there is the sympathetic bundle ventrally from the heads of the ribs ${ }^{23}$. The most frequent complications include pneumothorax ( $0.2 \%$ to $2.5 \%)$ and intercostobrachial neuralgia $(0.2 \%$ to $3 \%)$.

The success rate of RF-TSE is lower than in case of thoracoscopic sympathectomy where direct visual control is used during interruption of the sympathetic bundle. Due to lower risks and higher comfort for the patient, it is however an appropriate alternative or supplement to the therapeutic algorithm of severe vasospastic disorders in the upper limbs. Wilkinson describes in his study from 1996 the results in a group of 110 patients in whom 
there were totally 247 RF sympathectomies performed. Immediate success was approaching 100\%, after 6 months there was a great effect still in $90 \%$ of patients and after 3 years in more than $70 \%$ of the patients. Regarding the complications, the author reported six cases of pneumothorax $(2.4 \%)$, twice persistent Horner syndrome $(0.8 \%)$ and ten patients $(4.0 \%)$ with intercostobrachial neuralgia $^{24}$. The greatest group of RF destructions of the upper thoracic sympathetic nerves comes from Chuang and Liu who performed 1742 RF thermocoagulations indicated for palmar and facial hyperhidrosis. The success rate exceeded $90 \%$ and frequency of complications was very low $-0.2 \%$ for pneumothorax and $0.15 \%$ for permanent Horner's syndrome. The occurrence of intercostobrachial neuralgia was not reported by the authors ${ }^{25}$. Some departments use a combination of RF sympathectomy at the level T2 and subsequent application of $0.5 \mathrm{ml}$ of $6 \%$ phenol. This quantity of neurolytic agent is safe in comparison with previously performed chemical sympathectomy ${ }^{26}$. The study of Gabrhelík et al. compared the effect of RF-TSE at the level T2 and T3 and combined radiofrequency and chemical ablation of the sympathetic ganglion in patients with Raynaud's phenomenon. The changes were evaluated using a visual analogue scale of pain and thermographic examination. It has shown statistically significant reduction of pain and increased temperature at rest in the peripheral parts of the upper limbs in both methods ${ }^{27}$. The level of available reports according to evidence-based medicine is at the level of class II (ref. ${ }^{27}$ ) or class III ( ref. $^{25,28}$ ).

Presented case reports demonstrate success of RFTSE in the treatment of severe perfusion disorders of the upper limbs of combined origin. Complete healing of chronic defects, improvement of pain and cold sensations was reported in all followed up patients. Two out of free patiens were diabetics who are relatively contraindicated to sympathectomy procedures. Expected autosympathectomy theoreticaly caused by the diabetic neuropathy is unconfirmed and unproven. Sympathectomy of any sort may be beneficial for diabetics if tonus of sympathetic system is partially preserved (diagnostic sympathetic blockade) $\left(\right.$ ref. $\left.^{29}\right)$. Patient in a case report 1 underwent regular haemodialysis using an AV shunt in the left antecubital fossa which may cause steal phenomenon. Otherwise, necroses were present on the fingers of both hands and RF-TSE has been beneficial for healing all of them. The effect persists for several months after the procedure. Possible benefit significantly exceeds the risks of the method. Severe complications were not observed. From the insignificant complications was observed pain at the puncture site in 1 patient which subsided within 3 days after the procedure.

\section{CONCLUSION}

Patients with impaired perfusion of the upper limbs with chronic defects in the hands suffer from significant medical and social problems. Despite variable origin of vasospastic conditions the conservative approach is similar in each case. This approach however fails in severe perfusion impairments associated with development of chronic skin defects. These are serious conditions associated with long-term therapy with uncertain result. The patients often end up with amputation of phalangae or whole fingers on the hands with subsequent problems with grip, significant pain and overall disability. Therefore the treatment algorithm includes also invasive treatment methods. Radiofrequency thoracic sympathectomy could improve peripheral perfusion of the upper limbs and thereby contributes to healing of chronic defects, reduction of pain and improvement of quality of life of the patients. RF-TSE due to its minimal demandingness and invasiveness offers a unique possibility to repeat the procedure easily and with a minimal risk for the patient in case of recurrence of his/her complaints.

\section{REFERENCES}

1. Distler M, Distler J, Ciurea A, Kyburz D, MillerLadner U, Reich K, Distler O. Evidence-based therapy of Raynaud's syndrome. Z Rheumatol 2006;65:285-9.

2. Staněk F. Vazospastická onemocnění. In: Karetová $D$, Staněk F. (Eds.) Angiologie pro praxi. Praha: Maxdorf;2001,96-104.

3. Svoboda J. Onemocnění cév. In: Kordač V. (Eds.) Vnitřní lékařství II. Praha: Avicenum; 1991. p. 53-5.

4. Higuchi Y, Nashold BS, Sluijter ME, Cosman E, Pearlsein RD. Exposure of the dorsal root ganglion in rats to pulsed radiofrequency currents activates dorsal horn lamina I and II neurons. Neurosurgery 2002;50:850-6.

5. Gabrhelik T, Michalek P, Adamus M, Mikova M, Dolecek L. Effect of pulsed radiofrequency therapy on the suprascapular nerve in shoulder pain of various aetiology. Irish Journal of Medical Science 2010; 179(3):369-373.

6. Stanton-Hicks M. Thoracic sympathetic block: a new approach. Tech Reg Anesth Pain Manager 2001;6:94-8.

7. Sluijter ME. Radiofrequency, part 2: Thoracic and Cervical Region, Headache and Facial Pain. Meggen, Switzerland: FlivoPress SA; 2003. p. 129.

8. Moya AJ, Prat OJ, Torera AR, Ramos IR, Villalonga BR, Ferrer RG. Sympathetic dermatomes corresponding to T2 and T3 ganglia. A prospective study of 100 superior thoracic sympathicolytic procedures. Arch Broncopneumol 2003;39:19-22.

9. Herrick AL. Pathogenesis of Raynaud's phenomenon. Rheumatology 2005;44:587-96.

10. Cooke JP, Marshall JM. Mechanisms of Raynaud's disease. Vasc Med 2005;10:293-307.

11. Dziadzio M, Denton CP, Smith R, Howell K, Blann A, Bowers E, Black CM. Losartan therapy for Raynaud's phenomenon and scleroderma: clinical and biochemical findings in fifteen-week, randomized, parallel group, controlled trial. Arthritis Rheum 1999;429:2646-55.

12. Chotani MA, Flavahan S, Mitra S, Daunt D, Flavahan NA. Silent a2adrenergic receptors enable cold-induced vasoconstriction in cutaneous arteries. Am J Physiol Heart Circ Physiol 2000;278:1075-83.

13. Bunker CB, Reavley C, O'Shaughnessy DJ, Dowd PM. Calcitonin generelated peptide in treatment of severe peripheral vascular insufficiency in Raynaud's phenomenon. Lancet 1993;342:80-3.

14. Pope J, Fenlon D, Thompson A, Shea B, Furst D, Wells G, Silman A. lloprost and cisaprost for Raynaud's phenomenon in progressive systemic sclerosis. Cochrane Database Syst Rev 2000;2:CD000953.

15. George JL, Thomson MB. A clinical trial of Gingko Biloba extract in patients with intermittent claudication. Int Angiology 1990;9:75-8.

16. Štádler P, Šebesta P, Klika T. Torakoskopická horní hrudní sympatektomie jako metoda volby reoperace na hrudním sympatiku. Rozhl Chir 1999;78:448-50.

17. Matsumoto $Y$, Ueyama $T$, Endo M, Sasaki H, Kasashima F, Abe $Y$, Kosugi I. Endoscopic thoracic sympathicotomy for Raynaud's phenomenon. J Vasc Surg 2002;36:57-61.

18. Thune TH, Ladegaard L, Licht PB. Thoracoscopic sympathectomy for Raynaud's phenomenon - a long term follow-up study. Eur J Vasc Endovasc Surg 2006;32:198-202. 
19. Leriche R, Fontaine R. L'anesthésie isolée du ganglion étoilé. Presse Méd 1934;41:835.

20. Dondelinger RF. Percutaneous phenol block of the upper thoracic sympathetic chain with computed tomography guidance. Acta Radiol 1987;28:511-5.

21. Tsai JC, Lim KB, Lin SY, Kao MC. Thermographic study of palmar and facial skin temperature of hyperhidrosis patients before and after thoracic sympathectomy. J Formos Med Assoc 2000;99:466-71.

22. Dutka J. Blokáda hrudního sympatiku. V: Dutka J, Michálek $P$, Masopust $V$, editors. Intervenční postupy v léčbě bolesti - vegetativní nervový systém. Praha: MUDr. Pavel Michálek - B.A.R.;2002. p. 97-103.

23. Stevens RA, Ruesch S. Sympathetic blocks of the upper extremity and their complications. Tech Reg Anesth Pain Manager 1998;2:130-6.

24. Wilkinson HA. Percutaneous radiofrequency upper extremity sympathectomy. Neurosurgery 1996;38:715-25.
25. Chuang KS, Liu JC. Long-term assessment of percutaneous stereotactic thermocoagulation of upper thoracic ganglionectomy and sympathectomy for palmar and craniofacial hyperhidrosis in 1742 cases. Neurosurgery 2002;51:963-70.

26. Gofeld $M$, Faclier G. Bilateral pain relief after unilateral thoracic percutaneous sympathectomy. Can J Anaesth 2006;53:258-62.

27. Gabrhelik T, Michalek P, Adamus M, Berta E. Percutaneous Upper Thoracic Radiofrequency Sympathectomy in Raynaud Phenomenon: A Comparison of T2/T3 Procedure Versus T2 Lesion With Phenol Application. Reg Anesth Pain Med 2009;34:425-9.

28. Michálek P, Gabrhelík T, Doleček L, Štádler P, Šebesta P, Roztočil K. Radiofrekvenční denervace hrudního sympatiku-nová možnost v léčbě ischemických stavů horních končetin. Cor Vasa 2007;49:13-18.

29. Michálek P, Dutka J, Adamec M, Janousek L, Roztocil K. Percutaneous lumbar sympathectomy - presentation of a new trans-discal approach. Rozhl Chir. 2000;79(11):516-20. 